\title{
Recorrido por el patrimonio geológico y minero del Bajo Aragón, desde Seno a Aguaviva, Mas de las Matas, Foz - Calanda y Alcorisa
}

Josep Maria Mata-Perelló

Andrés Pocoví Juan

Joaquim Sanz Balagué

Jaume Vilaltella

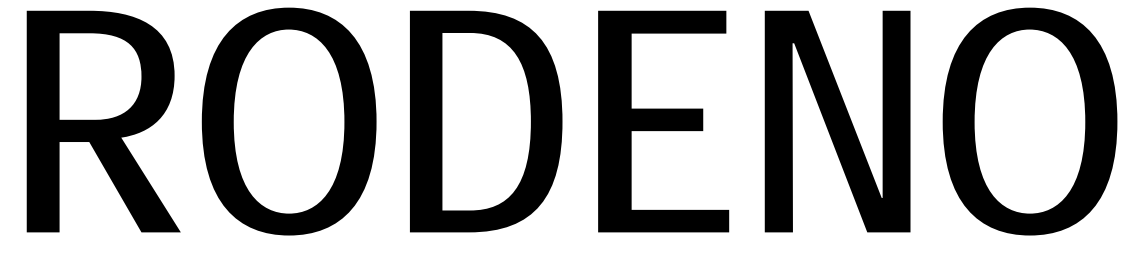

\section{REVISTA DE GEOLOGÍA ARAGONESA}

\section{n. 2}

JUNIO 2015 


\title{
RECORRIDO POR EL PATRIMONIO GEOLÓGICO Y MINERO DEL BAJO ARAGÓN, DESDE SENO A AGUAVIVA, MAS DE LAS MATAS, FOZ - CALANDA Y ALCORISA
}

\author{
Josep Maria Mata-Perelló \\ Museu de geologia Valentí Masachs, Escola Politècnica Superior d'Enginyeria de Manresa \\ (EPSEM), Universitat Politècnica de Catalunya · BarcelonaTech (UPC), 08272 Manresa, Spain
}

\author{
Andrés Pocovi Juan \\ Universidad de Zaragoza, Departamento de Ciencias de la Tierra ( DCT- UZ) \\ Joaquim Sanz Balagué \\ Departament d'Enginyeria Minera i Recursos Naturals (EMRN), Escola Politècnica Superior \\ d'Enginyeria de Manresa (EPSEM), Universitat Politècnica de Catalunya - BarcelonaTech \\ (UPC), 08272 Manresa, Spain
}

\section{Jaume Vilaltella Farràs.}

Sociedad Española para la Defensa del Patrimonio Geológico y Minero (SEDPGYM)

\section{Palabras clave: patrimonio minero; patrimonio geológico; Zaragoza}

\section{Resumen}

En esta ocasión se realizará un itinerario localizado en un área totalmente situada en la comarca del Bajo Aragón, desde principio a fin, entre las localidades de Seno y Alcorisa, pasando además por los municipios de Aguaviva, Foz Calanda y la Ginebrosa (en este caso, muy tangencialmente).

Por otra parte, el recorrido se centrará en su totalidad en el Sistema Ibérico. Encontrándose diferentes afloramientos de los materiales mesozoicos y de los materiales cenozoicos.

En el primer caso, nos encontraremos fundamentalmente con afloramientos de los materiales del Jurásico y sobretodo del Cretácico, fundamentalmente del Albiense. Precisamente, algunas de las diferentes paradas del recorrido las efectuaremos en los afloramientos de la Formación Utrillas y otros en los de la Formación Escucha. Por lo que concierne a los afloramientos de los materiales cenozoicos, cabe señalar que en su mayoría pertenecen al Oligoceno, el cual recubre parte de las formaciones mesozoicas mencionadas anteriormente.

No obstante, a lo largo del recorrido nos centraremos fundamentalmente en el conocimiento del Patrimonio Geológico y Minero. Sin duda alguna, la conservación, valorización y utilización de este patrimonio es un importante factor económico a tener en cuenta. 


\section{Objetivos generales de este itinerario}

En la realización de este itinerario geológico y minero, se perseguirá la consecución de los siguientes objetivos generales, a lo largo del desarrollo del mismo:

1. Observación general de la estructura del Sistema Ibérico, a través del cual se desarrollará la totalidad del recorrido del itinerario. En concreto, el recorrido se va a realizar íntegramente por los sectores correspondientes a la Rama Aragonesa; muy cerca de su contacto con la Depresión Geológica del Ebro.

2. Observación de los materiales geológicos del Mesozoico que constituyen los afloramientos del Sistema Ibérico, por los alrededores de los municipios de Seno, Ginebrosa, Foz Calanda y Alcorisa; a través de los cuales discurrirá parte del itinerario. Estos materiales se distribuyen fundamentalmente entre el Jurásico y el Cretácico; aunque en su mayor parte pertenecen a este último.

3. Observación de los materiales geológicos del Cenozoico que constituyen parte de los afloramientos del Sistema Ibérico, por los alrededores de los municipios del Mas de las Matas, Aguaviva y Alcorisa, a través de los cuales discurrirá parte del itinerario. Estos materiales se distribuyen fundamentalmente entre el Eoceno Superior y el Oligoceno; aunque en su mayor parte pertenecen a este último.

4. Observación de las diferentes explotaciones mineras; tanto de las de carácter subterráneo como de las realizadas a cielo abierto (que son las que ahora predominan) Estas explotaciones se hallan dedicadas a la extracción de los niveles caoliníferos en su mayoría y también a los lignitíferos. Se sitúan siempre entre los afloramientos de los materiales cretácicos pertenecientes según los casos a la Formación Utrillas o a la Formación Escucha.

5. Observación de los impactos producidos por las explotaciones mineras sobre el Medio Natural. Y también de la corrección de estos impactos. Aunque cabe decir que ninguna de las explotaciones que vamos a ver en este recorrido, ha tenido nunca ninguna restauración ambiental.

6. Observación del Patrimonio Geológico, como es el caso de los distintos afloramientos de los niveles lignitíferos.

7. Observación del Patrimonio Minero generado a partir de las explotaciones anteriores; así como de otras que iremos encontrando a lo largo de este itinerario. 


\section{Antecedentes bibliográficos}

No conocemos la existencia de ningún itinerario similar al que ahora presentamos. Hay, eso si, algunos recorridos nuestros que discurren por lugares cercanos. Entre ellos citaremos dos trabajos anteriores nuestros: MATA-PERELLÓ, J.M. (1996a, 1996b y 2003).

Por otra parte, en relación con las mineralizaciones situadas en la comarca por la que discurre este itinerario, haremos mención de otro trabajo nuestro: MATA-PERELLÓ (1992), referidos al inventario mineralógico de esta comarca.

$\mathrm{Y}$, finalmente, por lo que concierne a la estructura geológica de la zona por la que va a discurrir el itinerario, haremos mención de los trabajos de: GUIMERÀ et altri (1982) y de RIBA et altri (1976), los dos son de carácter generalista.

Todos ellos figuran en el apartado dedicado a la BIBLIOGRAFIA, al final del informe del recorrido del itinerario.

\section{Recorrido del itinerario}

El recorrido se desarrollará íntegramente por la comarca del Bajo Aragón. Así se iniciará en el municipio de Seno, en donde se efectuará la primera parada en la antigua Tejera de Seno.

Luego, el recorrido se dirigirá al cercano municipio del Mas de las Matas, por donde se efectuará una nueva parada, en la Yesería. Tras ello, se realizará una hijuela hacía el municipio de de Aguaviva y hacía el la Ginebrosa. En el primero se efectuará una parada en la Yesería, y en el segundo en la Tejera del Bergantes.

Tras regresar al Mas de las Matas, el recorrido continuará hacía Foz Calanda, atravesando parte del municipio de la Ginebrosa. En este recorrido se efectuaran diversas paradas en antiguas explotaciones lignitíferas y cerca de actuales explotaciones caoliníferas. Asimismo, en Foz Calanda, se hará una parada en el Horno de Alfarería.

Seguidamente, el recorrido se dirigirá hacía Alcorisa, en donde se efectuaran algunas paradas en las cercanías de actuales explotaciones caoliníferas. Precisamente, en este municipio finalizará el recorrido de este itinerario.

\section{Advertencias previas}

Como en otros recorridos de RECERCA GEOLÒGICA I MINERALÒGICA... si se dispone del tiempo suficiente, podrán efectuarse todas las paradas e hijuelas indicadas en el guión. En caso contrario, recomendamos prescindir de las denominadas PARADAS - CONDICIONALES.

También es necesario, en todo momento, tener en cuenta que una parte del recorrido se efectuará por caminos de tierra, circunstancia por la cual convendrá tomar las debidas precauciones. Así se hará el recorrido, primero entre Seno y la Tejera de Seno. O como el acceso a la Yesera del Mas de las Matas, entre otros recorridos.

Por último y como siempre, hay que tener a lo largo de todo el recorrido, un cuidado muy especial con la Naturaleza. 


\section{Descripción del itinerario}

Como ya es habitual, el recorrido del itinerario se estructurará sobre la base de una serie de PARADAS o ESTACIONES. En cada una de ellas se procederá a la observación de diferentes cuestiones específicas, ya sean mineras, geológicas o de tratamiento industrial de los materiales geológicos extraídos. En cada caso se indicará el número de la parada en el orden general del recorrido, el nombre de la misma (que podrá coincidir con el de la mina o el topónimo más cercano).

Tras ello se indicará el nombre del municipio en donde se halla la parada, y el de la comarca. Seguidamente se indicará el número del mapa topográfico (a escala 1:50.000) en donde se halla la parada. En este itinerario, utilizaremos exclusivamente las siguientes hojas editadas por el instituto Geográfico y Catastral de España: la nº 494 (Ilamada de Calanda) y la 519 (Ilamada de Aguaviva).

Así pues, a lo largo del presente itinerario que ahora se inicia, veremos las siguientes paradas:

PARADA 1. TEJERA DE SENO, (término municipal de Seno, comarca del Bajo Aragón). (Hoja 519).

El recorrido cabe iniciarlo en la localidad de Seno, la más occidental de la comarca del Bajo Aragón. Desde el pueblo, cabe coger el camino carretero (en buena parte asfaltado) que se dirige hacía Molinos y Berge. Al llegar al collado, convendrá hacer la primera parada, concretamente en la Tejera de Seno, a unos 2-3 Km del pueblo.

En este recorrido, hemos encontrado fundamentalmente afloramientos de la Formación Utrillas, en buena parte recubiertos por terrenos cuaternarios de derrubios de pendiente. Precisamente, en el lugar de la parada afloran los materiales de la Formación Utrillas, con niveles de caolines y arenas, a veces con gran contenido de óxidos de hierro (en especial de HEMATITES y GOETHITA). No obstante, los minerales mayoritarios son la CAOLINITA y el CUARZO.

Los materiales arcillosos (la CAOLINITA) fue aprovechada en su momento, para proporcionar materia prima para la tejera. Ésta, se halla en un estado de conservación bastante deplorable, aunque sigue en pie. No obstante, es un punto interesante del Patrimonio Minero del Bajo Aragón y convendría velar por su conservación. (fotografia 1). 


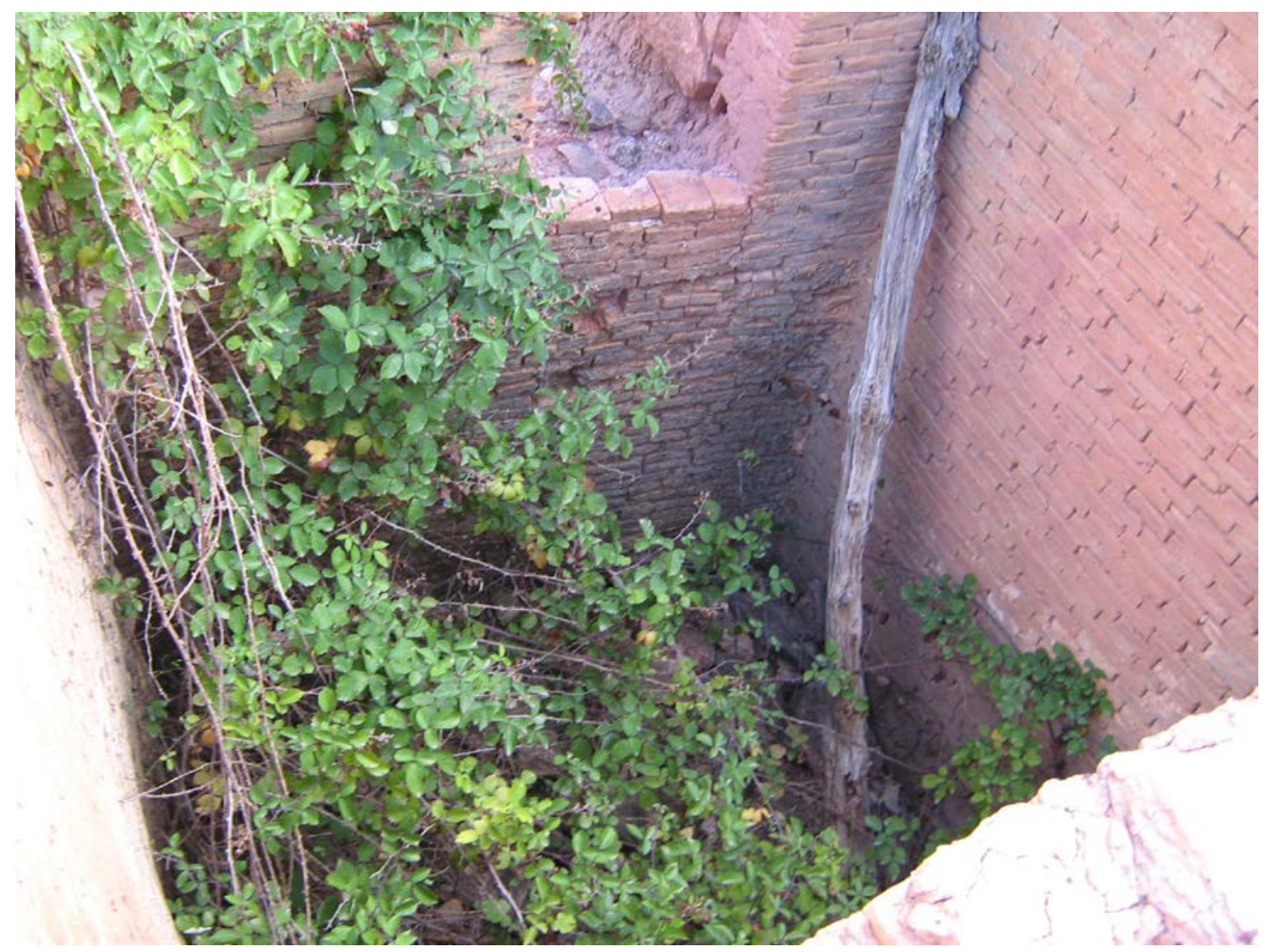

Fotografía 1. Tejera de Seno. Interior del horno

PARADA 2. YESERÍA DEL MAS DE LAS MATAS, (término municipal del Mas de las Matas, comarca del Bajo Aragón). (Hoja 494).

Tras realizar la parada anterior, cabe retornar a Seno, para ir después hacía la carretera autonómica que enlaza los pueblos de Castellote y el Mas de las Matas. Al llegar a esta carretera, yendo ahora hacía el poniente, pronto se llegará a las inmediaciones de Abenfigo, tras entrar a la comarca del Maestrazgo. Más adelante, al retornar a la comarca del Bajo Aragón, se llegará pronto al Mas de las Matas. Una vez ahí, será necesario coger la carretera autonómica que se dirige hacía Alcorisa. No obstante, a algo más de $2 \mathrm{Km}$ del Mas de las Matas, cabe coger un camino que va hacía la izquierda. Este camino nos llevará a la Yesería del Mas de las Matas. Ahí haremos una nueva parada, a unos $10 \mathrm{Km}$ de la anterior.

En este recorrido, hemos ido encontrando afloramientos cretácicos, como los situados cerca de Abenfigo. Entre estos materiales, muy carbonatados, habremos encontrado diversos "hardground" ferruginosos, claramente ostensibles. Luego, en las inmediaciones del Mas de las Matas habremos encontrado diversos afloramientos de los materiales cenozoicos, como los que se encuentran cerca del lugar de la parada. A menudo, estos materiales se hallan recubiertos por sedimentos cuaternarios.

En el lugar de la parada se hacen ostensibles unos afloramientos de niveles cenozoicos yesosos. Éstos han sido explotados como materia prima para la yesería en donde ahora estamos. (fotografia 2). 


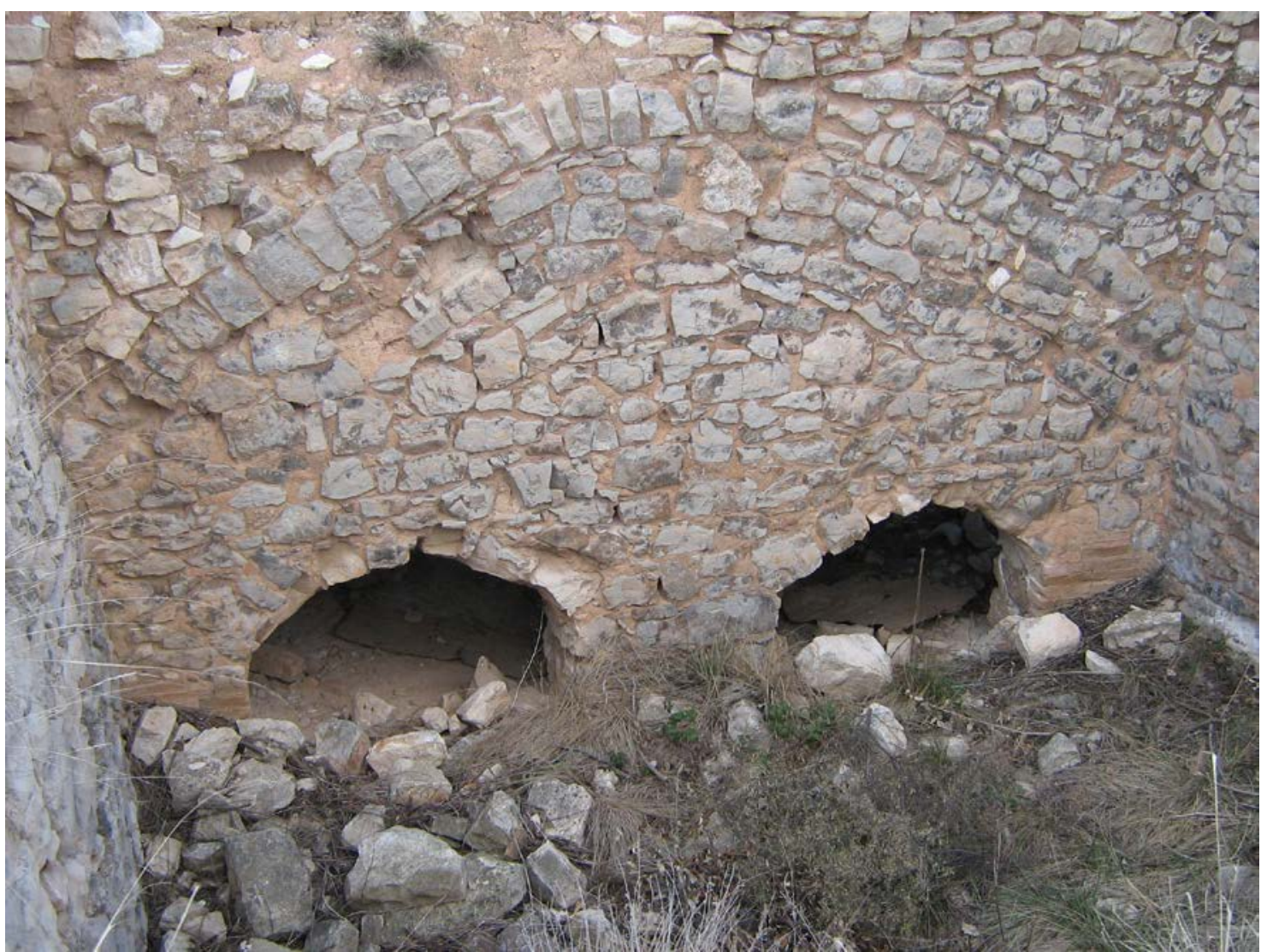

Fotografía 2. Bocas de dos de los hornos de la Yesería del Mas de las Matas

En este lugar se encuentra una interesante yesería, recientemente recuperada de las hierbas que la cubrían. Forma parte de nuestro Patrimonio Minero y sería conveniente velar por su conservación. 
PARADA 3 - CONDICIONAL. YESERÍA DE AGUAVIVA, (término municipal de Aguaviva, comarca del Bajo Aragón). (Hoja 519).

Tras realizar la parada anterior, cabe retornar al Mas de las Matas, para efectuar una hijuela hacía el cercano pueblo de Aguaviva. Poco antes de llegar a él, casi llegando a la gasolinera, podemos efectuar una nueva parada en la Yesería de Aguaviva. Esta se halla a la izquierda de la carretera. Así, desde la parada anterior habremos recorrido unos $5 \mathrm{Km}$ más.

En este recorrido habremos ido encontrando materiales cenozoicos (del Eoceno Superior y del Oligoceno). Estos son los materiales que hay junto al lugar de la parada, en donde afloran unos niveles de yesos. En su momento, estos fueron explotados como materia prima para ser utilizados en esta yesería, conjuntamente con los extraídos en las cercanías. Aquí, eran calcinados en unos hornos de yeso. (fotografia 3 ).

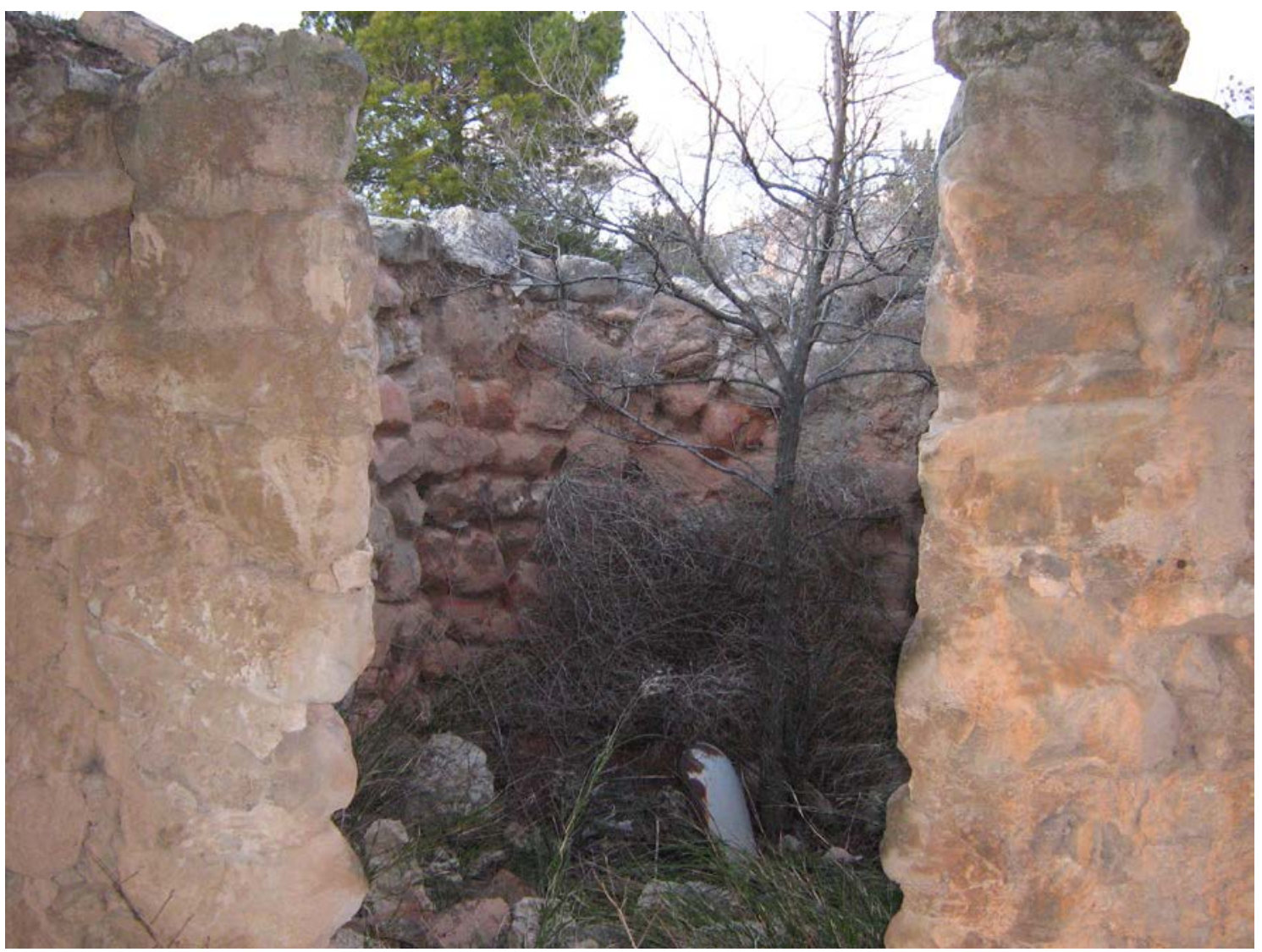

Fotografía 3. Uno de los hornos de yeso de la Yesería de Aguaviva

Cabe decir que este es uno de los hornos de yeso de la Yesería de Aguaviva. A pesar de su precario estado de conservación, es otro elemento importante del patrimonio minero del Bajo Aragón y sería aconsejable su conservación. 
PARADA 4 - CONDICIONAL. TEJERA DEL BERGANTES, (término municipal de la Ginebrosa, comarca del Bajo Aragón). (Hoja 519).

Después de efectuar la parada anterior, es necesario continuar por la hijuela iniciada en el Mas de las Matas. Así, tras llegar a Aguaviva, nos convendrá seguir hacía el límite del municipio, llegando al río Bergantes. Tras sobrepasarlo, encontraremos una tejera, entre la carretera y el río, a unos 100 metros del Bergantes. Ahí, en la Tejera del Bergantes, efectuaremos una nueva parada a unos $4 \mathrm{Km}$ de la anterior, y ahora dentro del municipio de la Ginebrosa.

En este recorrido, habremos ido encontrando afloramientos de los materiales que hemos mencionado en la parada anterior. A menudo estos materiales se hallan recubiertos por sedimentos detríticos cuaternarios, generalmente de origen fluvial.

En este lugar se hallan los restos (medianamente conservados) de una antigua tejera. En ella se utilizaban los materiales arcillosos cenozoicos extraídos en las cercanías. La tejera es muy interesante; y como los elementos que hemos visto antes, también forma parte del patrimonio minero del Bajo Aragón. (fotografía 4).

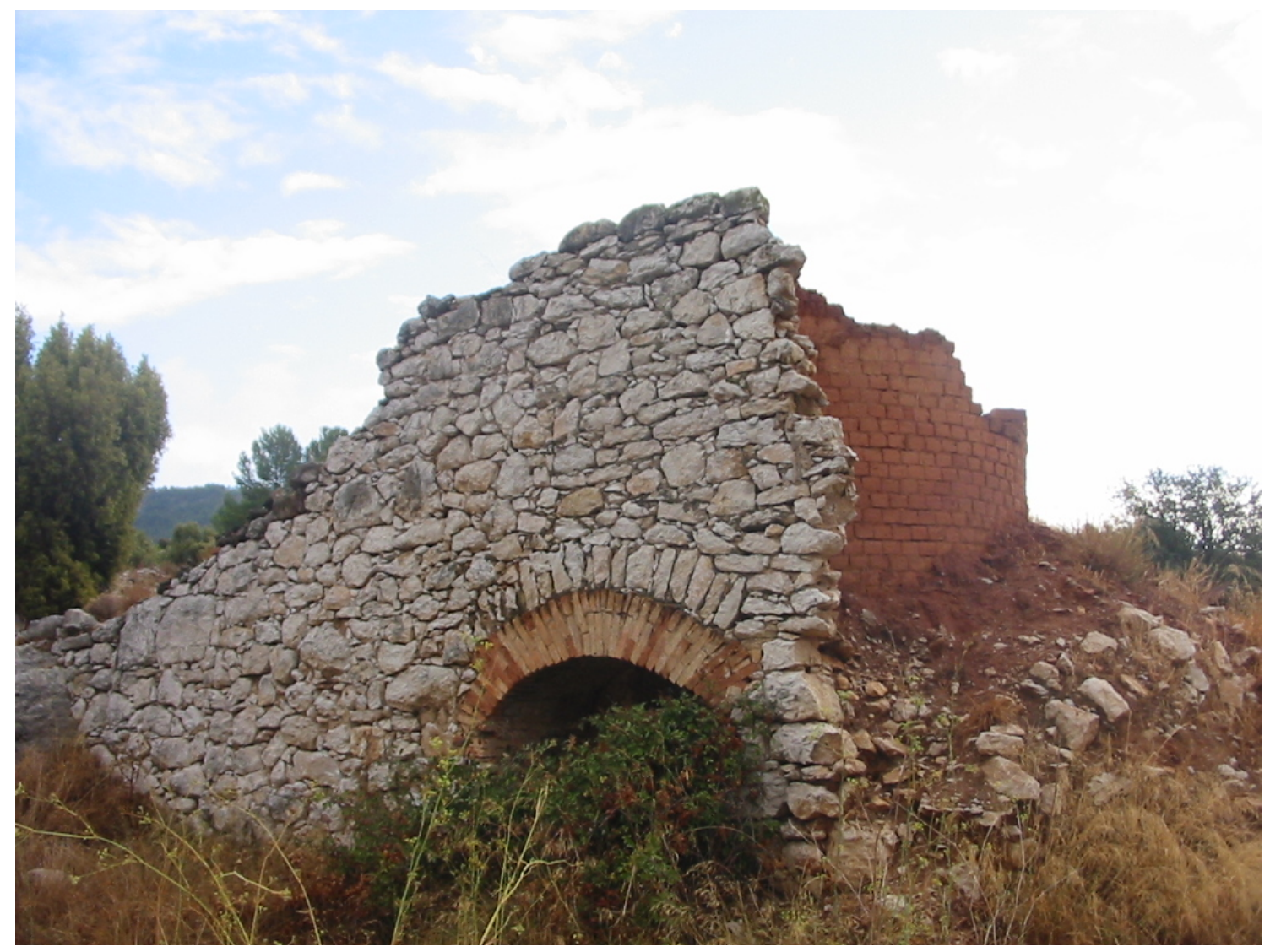

Fotografía 4. Tejera del Bergantes 
PARADA 5. EL CHORRADOR, (término municipal de la Ginebrosa, comarca del Bajo Aragón). (Hoja 5494).

Después de realizar la parada anterior, solo cabe terminar la hijuela. Así, convendrá regresar a Aguaviva y al Mas de las Matas. Luego, desde este pueblo, cabe seguir el recorrido del itinerario por la carretera que conduce hacía Calanda. A unos $4 \mathrm{Km}$ del Mas de las Matas, convendrá tomar un camino a la derecha que va descendiendo hacía el río Guadalupe. Ahí efectuaremos una nueva parada, a unos $12 \mathrm{Km}$ de la anterior.

En este recorrido hemos ido encontrando afloramientos de los materiales cenozoicos mencionados en la parada anterior. A menudo, estos materiales se hallan recubiertos por depósitos detríticos cuaternarios, fundamentalmente de origen fluvial. Incluso hemos pasado junto a algunas explotaciones que utilizaban estos materiales para la obtención de áridos.

Por otra parte, muy cerca del lugar de la parada, habremos encontrado unos afloramientos de niveles carbonatados mesozoicos. Precisamente, estos son los materiales que aparecen en el lugar de la parada. En este lugar aparece el río Guadalope (en la cola del embalse de Calanda), que va serpenteando entre estos materiales, tras haber recibido aguas arriba al río Bergantes. El lugar es de una gran belleza y forma parte del patrimonio geológico de esta comarca, con el río Guadalupe serpenteando meandriformemente entre los niveles carbonatados mesozoicos. (fotografía 5).

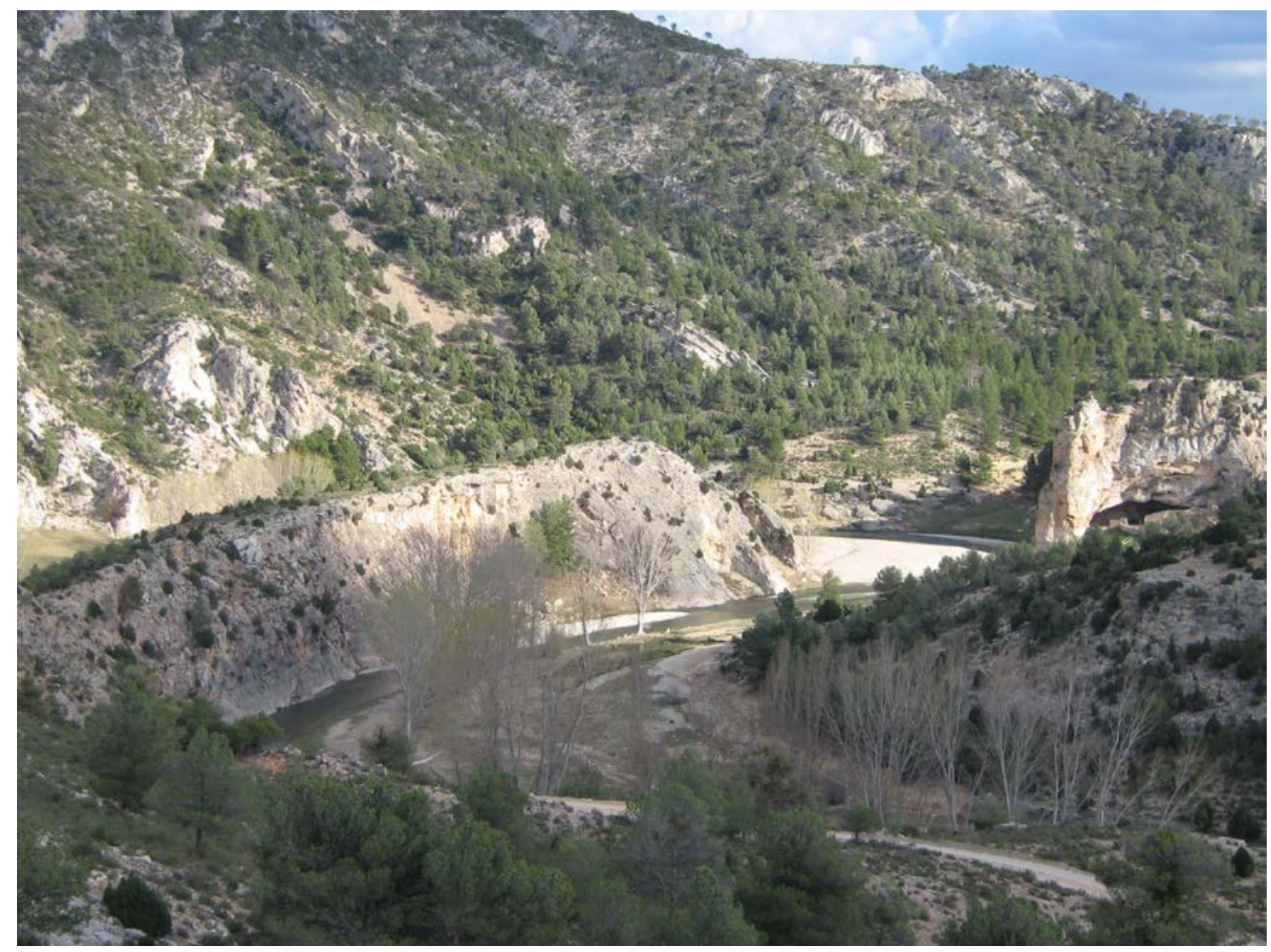

Fotografía 5. El río Guadalupe en el Chorrador 
PARADA 6. MINA DE LIGNITO DE LA GINEBROSA, (término municipal de la Ginebrosa, comarca del Bajo Aragón). (Hoja 494).

Tras realizar la parada anterior, cabe hacer otro recorrido breve, con la finalidad de llegar a la antigua Mina de Lignito de la Ginebrosa. Ahí, efectuaremos una nueva parada a unos $6 \mathrm{Km}$ de la parada anterior. La parada la intentaremos efectuar a la derecha de la carretera.

En este recorrido hemos ido encontrando afloramientos de los materiales mesozoicos, generalmente del Cretácico. Sin embargo, muy cerca del lugar de la parada, habremos visto ya afloramientos de los materiales de la Formación Escucha 8con tramos lignitíferos), Y por encima de ella, habremos encontrado los niveles caolínicos y arenosos de la Formación Utrillas. Así, muy cerca del lugar de la parada (a unos 100 metros antes de llegar), se observa un contacto entre unos y otros materiales.

En este lugar había una antigua explotación lignitífera que se había realizado por minería subterránea. Más adelante, esta explotación pasó a efectuarse por minería a Cielo Abierto, permaneciendo ahora abandonada. Precisamente, este corte nos permite ver los distintos niveles de lignitos, óxidos de hierro y caolines. (fotografia 6)

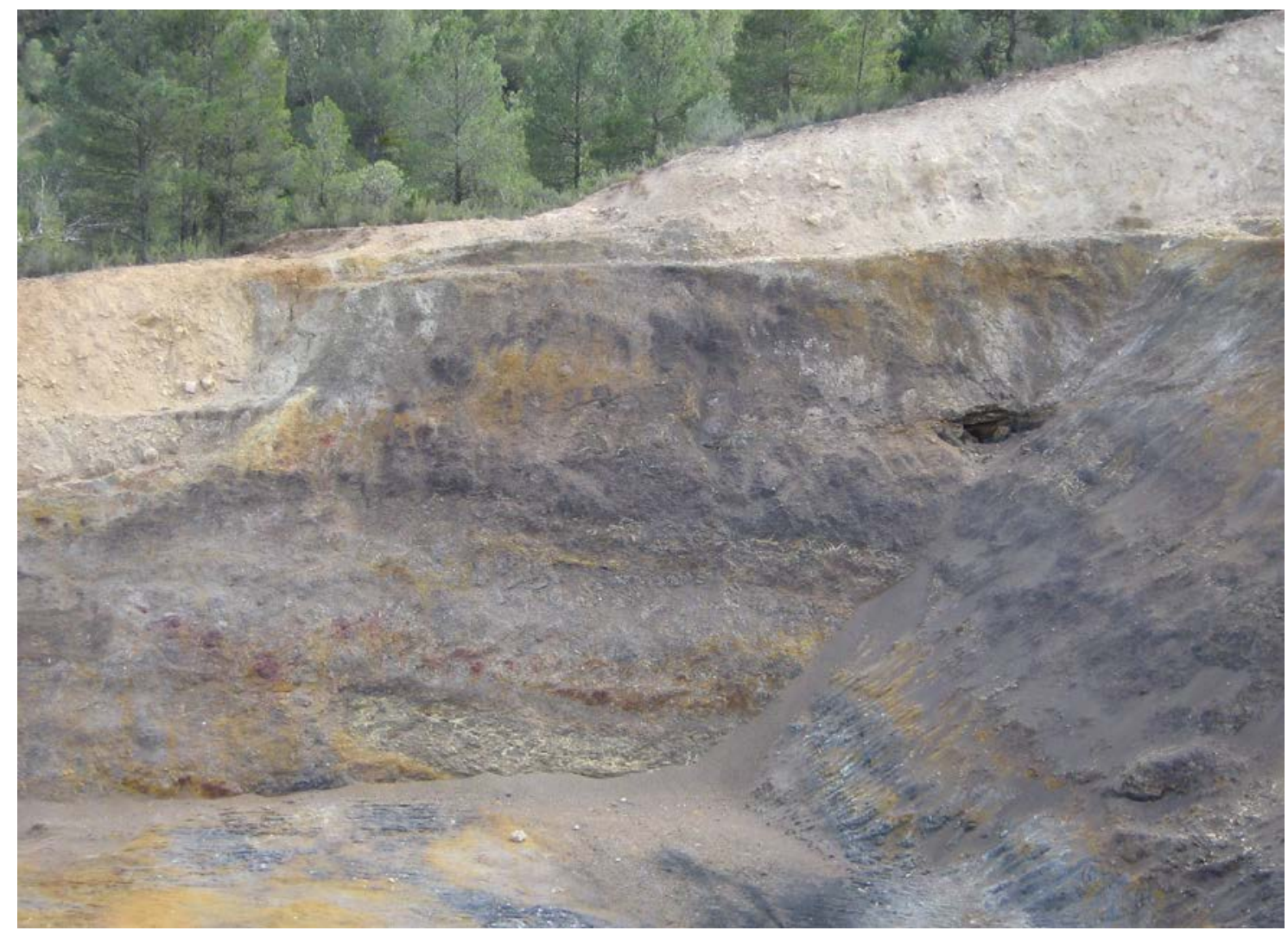

Fotografía 6. Mina a Cielo Abierto de la Ginebrosa 
Cabe indicar que en este lugar, especialmente en las escombreras, es posible encontrar diversos minerales. Así a partir de la PIRITA primaria incluida en los lignitos, se ha ido formando Ácido Sulfúrico (por acción del agua y del oxígeno). Este ácido ha atacado a la CALCITA presente entre la roca encajante, dando lugar a la formación de YESO (a veces con cristales de grandes dimensiones). Por otra parte, a partir de la oxidación de la pirita, se va formando GOETHITA (limonítica) y MELANTERITA.

Otros minerales presentes entre los materiales de la Formación Escucha (y de la Formación Utrillas) son: GOETHITA (limonítica), HEMATITES, CALCITA, CAOLINITA, CUARZO.

PARADA 7 - CONDICIONAL. EXPLOTACIONES A CIELO ABIERTO DEL VAL DE LA PIEDRA, (término municipal de Foz Calanda, comarca del Bajo Aragón). (Hoja 494).

Tras realizar la parada anterior, es necesario continuar por la carretera que conduce a Calanda. Sin embargo, al llegar al barranco de la Val de Piedra es conveniente tomar un camino que va ascendiendo hasta llegar a unas explotaciones lignitíferas realizadas a Cielo Abierto. Al llegar ahí, si se cree conveniente, puede efectuarse una nueva parada, tras pedir el permiso correspondiente, ya que las minas están en actividad. En cualquier caso, desde la parada anterior hasta este lugar habremos efectuado el recorrido de unos $4 \mathrm{Km}$. Uno de ellos desde la carretera.

En este recorrido habremos ido encontrando los materiales mesozoicos que hemos mencionado en la parada anterior. Éstos y todos los que hemos ido encontrando desde el inicio del recorrido, se hallan situados dentro del Sistema Ibérico, por donde continuará el resto del recorrido.

En este lugar hay una gran explotación realizada a Cielo Abierto. Parte de ella, en los frentes más orientales (los primeros que se encuentran al llegar) se están efectuando trabajos de restauración.

Por otra parte, antes de llegar a estas explotaciones se habrá visto la planta de tratamiento. Esta, por lo que parece, se halla en un estado de semiabandono, o de poca actividad. (fotografia 7).

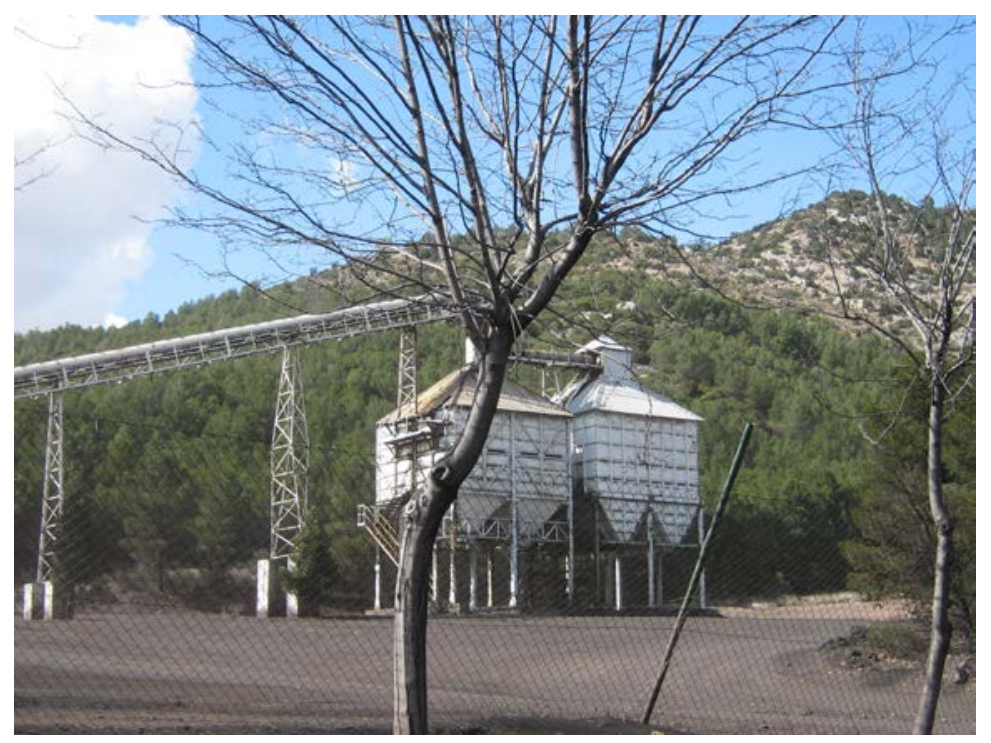

Fotografía 7. Planta de tratamiento de las explotaciones de Val de Piedra 
PARADA 8. HORNO DE ALFARERÍA, (término municipal de Foz Calanda, comarca del Bajo Aragón). (Hoja 494).

En cualquier caso, desde la parada anterior, es necesario continuar por la carretera que conduce a Calanda. Sin embargo, al encontrar el desvío que va a Foz Calanda, nos convendrá tomarlo para ir a este pueblo. Una vez ahí, casi a la entrada, será necesario ir hacía el Horno de Alfarería. En este lugar efectuaremos una nueva parada dentro de este recorrido, ahora tras recorrer unos $6 \mathrm{Km}$ más.

En este recorrido hemos ido encontrando afloramientos de los materiales mesozoicos mencionados en las paradas anteriores. Muy a menudo estos materiales son de naturaleza carbonatada, como los que están en el recorrido en el que se van encontrando diversos túneles.

En este lugar hay un interesante Horno de Alfarería, recientemente restaurado, Es uno más de los diversos hornos que había en este sector. En ellos se trabajaban las arcillas extraídas en diversos lugares de las cercanías. Se trabajaban con la misión de fabricar utensilios como cántaros.

Cabe indicar que este horno es otro elemento importante del patrimonio minero de esta comarca, siendo necesario velar por su conservación. Y también alabar la recuperación. Efectuada. (fotografia 8).

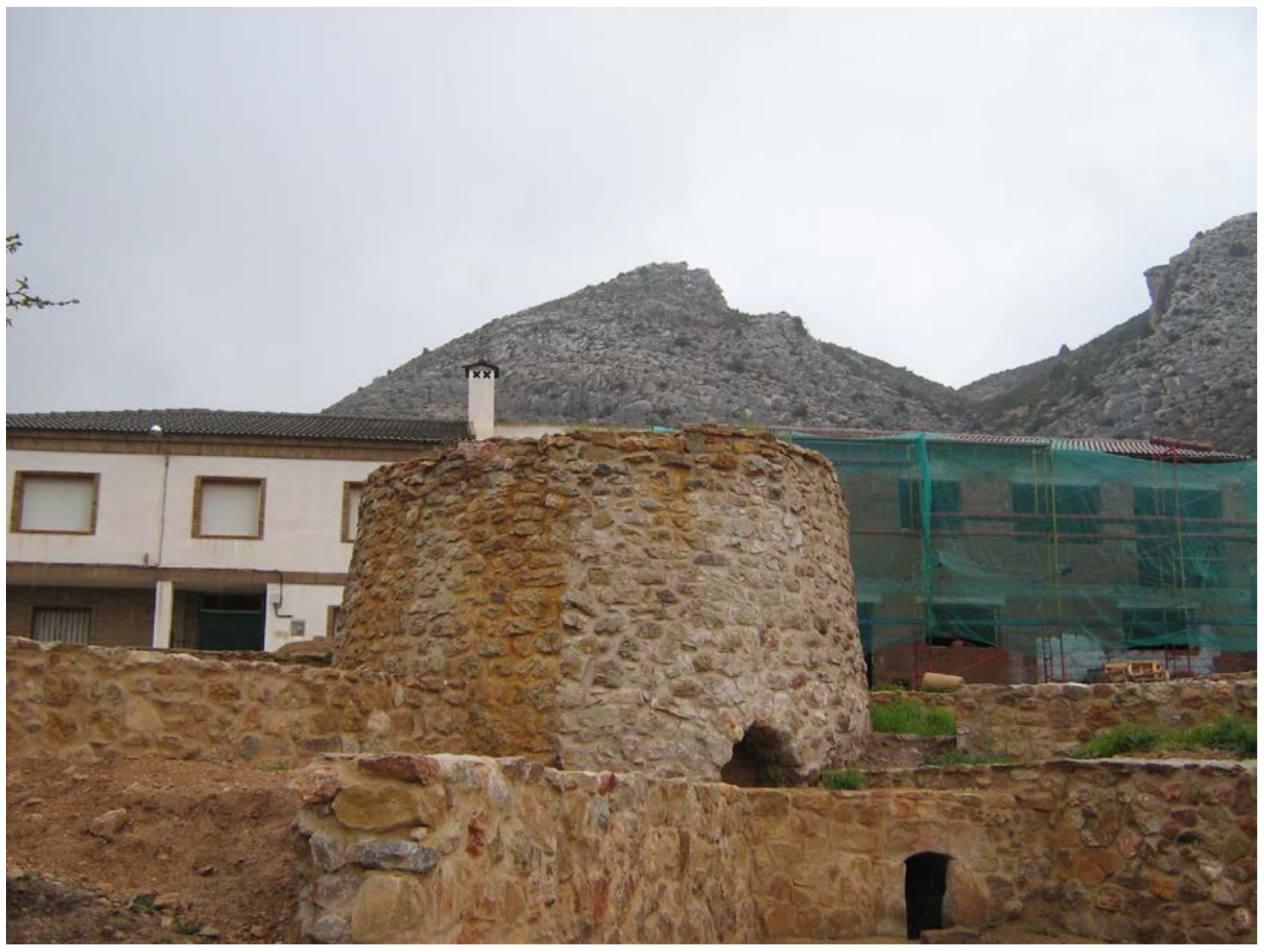

Fotografía 8. El Horno de Alfarería de Foz Calanda entre las casas del pueblo 
PARADA 9. EXPLOTACIONES DE CAOLIN DEL CERRO GALGA, (términos municipales de Foz Calanda y de Alcorisa, comarca del Bajo Aragón). (Hoja 494).

Tras realizar la parada anterior, cabe atravesar el pueblo de Foz Calanda, para continuar luego por una carreterita que conduce al Cerro Galga, y también a la carretera que luego va a Alcorisa. Al llegar al Cerro Galga, puede efectuarse una nueva parada, a unos $3 \mathrm{Km}$ de la anterior.

En este recorrido hemos ido encontrando afloramientos de los materiales carbonatados mesozoicos. Sin embargo, en el lugar de la parada afloran unos niveles de caolines y arenas, pertenecientes a la Formación Utrillas, del Albéense. Cabe indicar que estos materiales han sido explotados a Cielo abierto en diversos lugares de esta zona, tanto en el municipio de Foz Calanda como en el de Alcorisa. Sin embargo, ahora todas estas explotaciones están abandonadas. (fotografia 9).

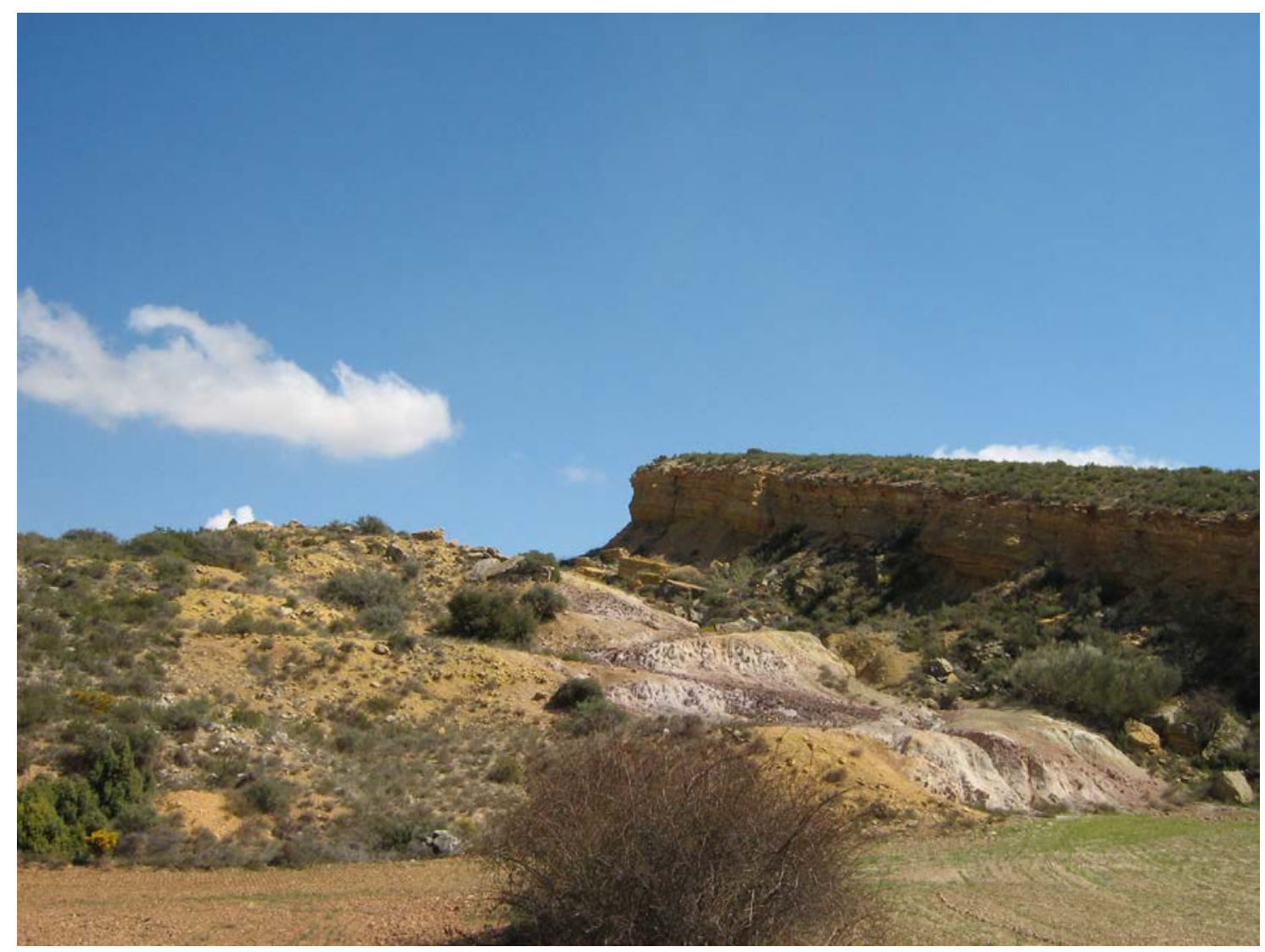

Fotografía 9. Una de las explotaciones del Cerro Galga 
PARADA 10. EXPLOTACIONES DE CAOLIN DEL CERRO OLIVEROS, (término municipal de Alcorisa, comarca del Bajo Aragón). (Hoja 494).

Después de efectuar la parada anterior, cabe continuar hacía Alcorisa. Luego, ahí será conveniente seguir por la carretera de Andorra, hasta encontrar el camino (por la izquierda) que va al Cerro Oliveros. Ahí haremos la última parada, a $4 \mathrm{Km}$ de la anterior.

En este recorrido, habremos vuelto a encontrar los materiales mesozoicos citados en las paradas anteriores, Asimismo, también encontraremos afloramientos de los materiales cenozoicos.

En este lugar hay diversas explotaciones caolíneferas, muchas en activo, situadas entre los materiales de la Formación Utrillas. En todo caso, seria pertinente pedir autorización para visitarla. (fotografia 10).

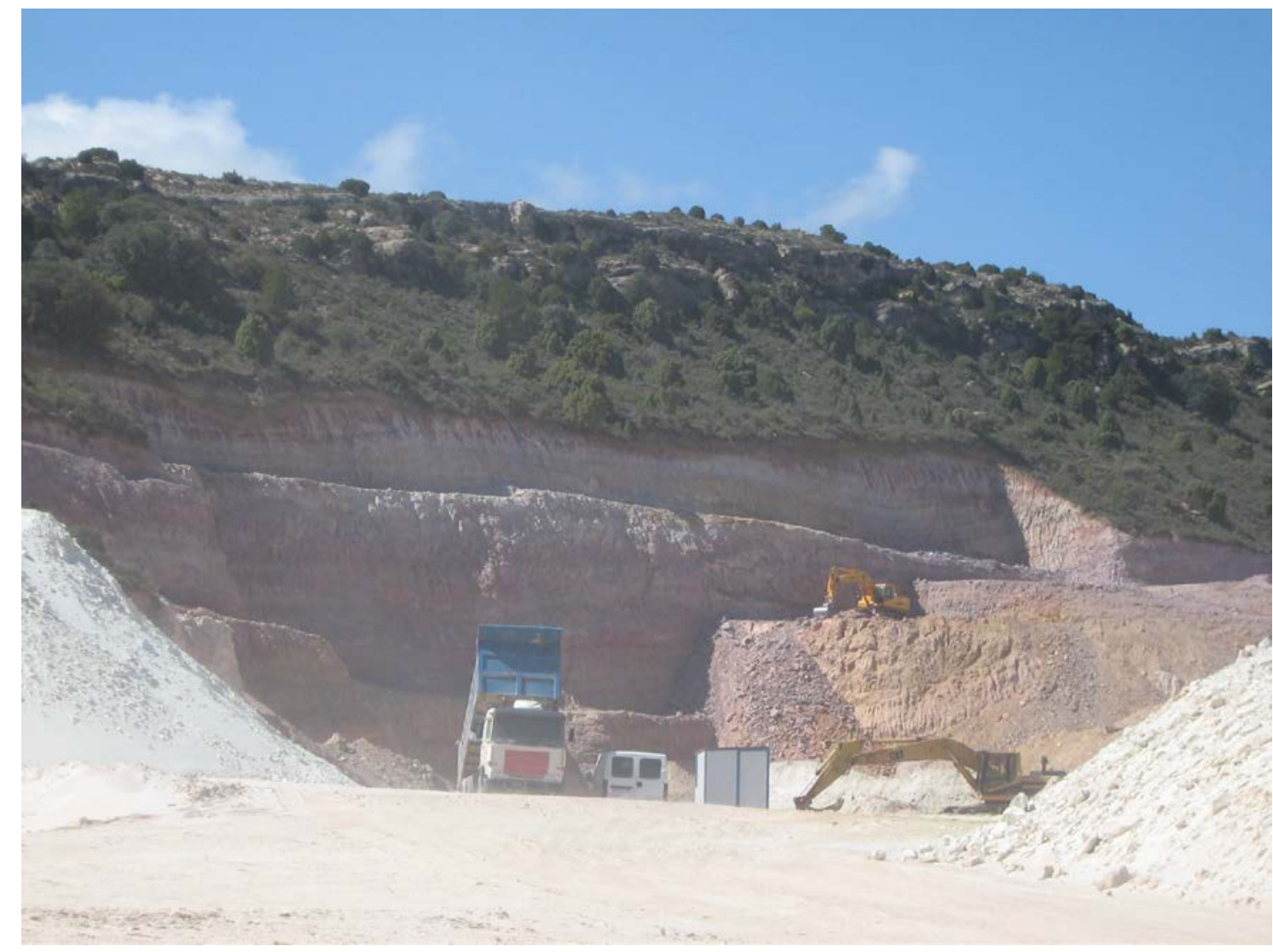

Fotografía 10. Una de las explotaciones de caolín de Alcorisa

EN ESTE LUGAR FINALIZA EL RECORRIDO DEL PRESENTE ITINERARIO 


\section{BIBLIOGRAFIA}

GUIMERÀ, J. et altri (1992).- Geologia (II), Història Natural dels Països Catalans, Vol. 2, 547 pag. Enciclopèdia Catalana, S.A. Barcelona.

MATA-PERELLÓ, J.M. (1992).- Inventario Mineralógico de la comarca de la Tierra Baja Guadalope (Aragón). Rodeno, 28, 20 pag. Manresa.

MATA-PERELLÓ, J.M. (1996a).- Itinerari geològico - mineralògic per les comarques del Matarranya i de la Tierra Baja-Guadalope: des de Calaceite a Valderrobres i Alcañiz. Inédito. 14 paginas. Manresa.

MATA-PERELLÓ, J.M. (1996b).- itinerari geològico - mineralògic per les comarques aragoneses de la Tierra de Montalbán, de la Tierra Baja-Martín i de la Tierra BajaGuadalope: des d’Alcañiz a Andorra, Aliaga i a la Zoma. Inédito. 20 paginas. Manresa.

MATA-PERELLÓ, J.M. (2003).- Itinerari geològic i mineralògic des d’Alcañiz a Morella passant per Foz Calanda, Aguaviva, Sorita, la Balma i Forcall. Inedito. 13 paginas. Manresa.

MATA-PERELLÓ, J.M. i SANZ BALAGUÉ, J. (1993).- Guía de identificación de Minerales, adaptada fundamentalmente a la Península Ibérica. Parcir, Edic. Selectas, 243 páginas. Manresa.

RIBA ARDERIU, O. et altri (1976).- Geografia Física dels Països Catalans. Edit Ketres. 211 pàgines. Barcelona. 